Карпенко Т.А.

\title{
СОВЕРШЕНСТВОВАНИЕ ПРАВОВОГО РЕГУЛИРОВАНИЯ АДМИНИСТРАТИВНОЙ ОТВЕТСТВЕННОСТИ ЗА НАРУШЕНИЕ ОБЩЕСТВЕННОГО ПОРЯДКА И ОБЩЕСТВЕННОЙ БЕЗОПАСНОСТИ ПРИ ПРОВЕДЕНИИ МАССОВЫХ МЕРОПРИЯТИЙ
}

\begin{abstract}
Аннотация. Предметом исследования являются правовые нормы, устанавливающие административную ответственность за нарущение общественного порядка и общественной безопасности при проведении массовых мероприятий. Автором рассматриваются нормативные правовые акты, устанавливающие запреты на организацию и проведение массовых мероприятий, регламентирующие порядок организации массовых мероприятий, регламентирующие порядок проведения массовых мероприятий. Особое внимание уделяется тому, что совокупность несогласованных правовых норм в данной сфере не позволяет выработать единую правовую модель административной ответственности за нарушение общественного порядка и общественной безопасности при проведении массовых мероприятий. В целях получения достоверных результатов использованы частнонаучные и специальные методы: сравнительно-правовой, логико-юридический, системноструктурный, и др., которые используются в совокупности и во взаимосвязи. В результате исследования законодательства об административной ответственности за нарушение общественного порядка и общественной безопасности при проведении массовых мероприятий как на федеральном уровне, так и на уровне субъектов Российской Федерации, разработана правовая модель административной ответственности за нарушение общественного порядка и общественной безопасности при проведении массовых мероприятий. Ключевые слова: административная ответственность, общественный порядок, общественная безопасность, массовое мероприятие, правовое регулирование, шествие, митинг, собрание, демонстрация, пикетирование
\end{abstract}

Review. The article studies the legal provisions establishing administrative responsibility for the violation of public order and public safety during mass events. The author considers the normative legal acts establishing prohibitions on organization and holding of mass events, regulating the organization of mass events. Particular attention is paid to the fact that the set of inconsistent legal norms in this area does not allow developing a common legal model of administrative responsibility for the violation of public order and public safety during mass events. In order to obtain reliable results the author uses special scientific methods: comparative legal, logical-legal, system-structural, et al., which are used in combination and interrelation. The analysis of the legislation on administrative responsibility for the violation of public order and public safety during public events at both federal and regional levels allows the author to create the legal model of administrative responsibility for the violation of public order and public safety during mass events.

Keywords: procession, legal regulation, mass event, public safety, public order, administrative responsibility, meeting, gathering, demonstration, picketing.

$\Pi$

равовым регулированием является воздействие на общественные отношения, осуществляемое при помощи права и иных юридических средств [1, с. 138].

Проблема совершенствования правового регулирования административной ответственности за нарушение общественного порядка и общественной безопасности при проведении массовых мероприятий является достаточно сложной и даже противоречивой, недаром в последнее время ей уделяется самое пристальное внимание.

Так, важнейшим документом в сфере укрепления защиты прав на свободу мирных собраний, является Всеобщая декларация прав человека от 10 декабря 1948 г. [2].

Во многом дополняют положения Всеобщей декларации прав человека Международный Пакт

«0 гражданских и политических правах» от 16 декабря 1966 г. и Международный пакт «Об экономических, социальных и культурных правах» от 16 декабря 1966 г. [3]. Так, Международный Пакт «0 гражданских и политических правах» провозглашает право на мирные собрания [4].

Исходя из содержания ст. 31 Конституции Российской Федерации одним из важнейших конституционных прав граждан является право собираться мирно, без оружия, проводить собрания, митинги, демонстрации, шествия, пикетирование. Вместе с тем на основе анализа нормативных правовых актов, реализующих положения ст. 31 Конституции Российской Федерации, а также юридической литературы можно прийти к выводу, что на сегодняшний день нет единого мнения по поводу содержания рассматриваемой статьи. 
Так, исходя из положений Федерального закона от 4 июня 2004 г. № 54-Ф3 «0 собраниях, митингах, демонстрациях, шествиях и пикетированиях» (далее - Федеральный закон № 54-Ф3) следует, что указанный нормативный правовой акт направлен на обеспечение реализации установленного Конституцией Российской Федерации права граждан собираться мирно, без оружия, проводить собрания, митинги, демонстрации, шествия, пикетирования [5].

Наряду с этим, согласно ст. 7 Федерального закона от 27 мая 1998 г. № 76-ФЗ «О статусе военнослужащих», военнослужащие вправе мирно, без оружия участвовать в публичных мероприятиях, проводимых вне территории воинской части в свободное от исполнения обязанностей военной службы время [6].

Между тем в ст. 26 Федерального закона от 11 июля 2001 г. № 95-Ф3 «0 политических партиях» определено, что политические партии вправе организовывать и проводить собрания, митинги, демонстрации, шествия, пикетирования и иные публичные мероприятия в порядке, установленном законодательством Российской Федерации [7]. Однако в данном случае не указывается формулировка «собираться мирно, без оружия».

Сказанное позволяет сделать вывод, что законодатель лишь перечисляет в различных вариантах положения ст. 31 Конституции Российской Федерации, но не раскрывает при этом дефиниции понятий «собираться мирно», «собираться без оружия».

Вместе с тем в юридической литературе также не существует единого мнения по поводу содержания ст. 31 Конституции Российской Федерации.

Ряд исследователей, комментируя рассматриваемую статью, отождествляет право собираться мирно, без оружия и право проводить собрания, митинги, демонстрации, шествия, пикетирование [8, с. 97], другие разделяют право собираться мирно, без оружия и право проводить собрания, митинги, демонстрации, шествия, пикетирование $[9$, c. 78], а некоторые указывают, что ст. 31 Конституции Российской Федерации содержит в себе две взаимосвязанные нормы: провозглашается право собираться мирно, без оружия и указывается, в каких формах оно может осуществляться [10, с. 88].

Тем не менее, на наш взгляд, данные нормы не идентичны.

Так, понятию «собираться» в контексте ст. 31 Конституции Российской Федерации присущ и мирный, и невооруженный характер.

Отметим, что среди ученых не выработано единого подхода по поводу того, какое мероприятие можно считать мирным.

Одни полагают, что наличие у участников публичного мероприятия оружия, даже если оно не используется, исключает мирный характер массовой акции [11, с. 50]. Другие считают, что отсутствие у участников мероприятия оружия не всегда говорит о мирном характере акции, а даже наоборот $[12$, с. 8]. Некоторые указывают, что выражение «мирно» в данном контексте означает отсутствие насильственного или подстрекательского характеpa $[13$, c. 17$]$.

Вместе с тем, согласно Руководящим принципам по свободе мирных собраний, подготовленным советом экспертов БДИПЧ ОБСЕ, собрание следует определять как мирное, если его организаторы имеют мирные намерения и собрания имеет ненасильственный характер. Термин «мирное» следует распространить на такое поведение, которое может раздражать или обижать других лиц, и даже на такое поведение, которое временно препятствует, затрудняет или создает помехи действиям третьих лиц [14].

В отличие от выражения «собираться мирно, без оружия», формулировка «проводить собрания, митинги, демонстрации, шествия, пикетирование» исходя из положений ст. 2 Федерального закона № 54-ФЗ может носить только мирный характер.

Однако из положений ст. 31 Конституции Российской Федерации, следует, что собрания, митинги, демонстрации, шествия, пикетирования также носят невооруженный характер. В соответствии с этим существует необходимость включить в определение «публичное мероприятие» указание на проведение последнего «без оружия».

Кроме того, отметим, что мирные собрания по своей природе являются массовыми мероприятиями [15]. Поэтому ст. 31 Конституции Российской Федерации охватывается право проводить различные виды массовых мероприятий. В силу чего необоснованной представляется позиция С. А. Авакьяна в части того, что законодателю не следует вводить новые виды массовых мероприятий, поскольку в ст. 31 Конституции Российской Федерации говорится только о собраниях, митингах, демонстрациях, шествиях и пикетированиях [16, с. 13$]$.

В соответствии с этим право собираться мирно, без оружия, на наш взгляд, включает в свое содержание проведение не только публичных мероприятий, но и иных массовых мероприятий.

Помимо этого правовое регулирование административной ответственности в исследуемой сфере представлено следующим образом:

1. Нормативными правовыми актами, устанавливающими запреты на организацию и проведение массовых мероприятий:

1.1. Запрет проведения или ограничение права на проведение массовых мероприятий в период действия чрезвычайного положения установлен ст. 11 


\section{Административное и муниципальное право 10 (94) 2015}

Федерального конституционного закона от 30 мая 2001 г. № 3-ФКЗ «0 чрезвычайном положении» [17];

1.2. Запрет на проведение или ограничение права проведения массовых мероприятий на территории, на которой введено военное положение, установлен ст. 7 Федерального конституционного закона от 30 января 2002 г. № 1-ФКЗ «О военном положении [18];

1.3. Запрет на организацию и проведение массовых акций или публичных мероприятий при приостановлении деятельности общественного объединения установлен ст. 43 Федерального закона от 19 мая 1995 г. № 82-ФЗ «Об общественных объединениях» [19];

1.4. Запрет на организацию и проведение массовых акций или публичных мероприятий в том случае, когда деятельность политической партии приостановлена, установлен ст. 40 Федерального закона «О политических партиях»;

1.5. Запрет на организацию и проведение массовых акции или публичных мероприятий в том случае, когда деятельность общественного или религиозного объединения приостановлена, установлен ст. 10 Федерального закона от 25 июля 2002 г. № 114-Ф3 «О противодействии экстремистской деятельности» [20].

2. Нормативными правовыми актами, регламентирующими порядок организации массовых мероприятий:

2.1. Порядок организации публичных мероприятий предусмотрен Федеральным законом № 54-Ф3;

2.2. Проведение индивидуальной профилактической работы с гражданами, совершившими административные правонарушения в рассматриваемой сфере, регламентируется Приказом МВД России от 31 декабря 2012 г. № 1166 «Вопросы организации деятельности участковых уполномоченных полиции» [21].

3. Нормативными правовыми актами, регламентирующими порядок проведения массовых мероприятий:

3.1. Вопросы агитации посредством проведения массовых мероприятий регламентируются ст. 60 Федерального конституционного закона от 28 июня 2004 г. № 5-ФКЗ «0 референдуме Российской Федерации» [22];

3.2. Проведение массовых мероприятий в пределах пятикилометровой полосы местности или до рубежа инженерно-технических сооружений в случаях, если он расположен за пределами пятикилометровой полосы местности, осуществляется на основании разрешения пограничных органов, что предусмотрено ст. 18 Закона Российской Федерации от 1 апреля 1993 г. № 4730-1 «0 Государственной границе Российской Федерации» [23];
3.3. Участие соединений и воинских частей оперативного назначения, специальных моторизованных соединений и воинских частей совместно с органами внутренних дел в охране общественного порядка и обеспечении общественной безопасности при проведении массовых мероприятий предусмотрено положениями ст. 18 Федерального закона от 6 февраля 1997 г. № 27-ФЗ «0 внутренних войсках Министерства внутренних дел Российской Федерации» [24];

3.4. Порядок проведения молитвенных и религиозных собраний устанавливается ст. 16 Федерального закона от 26 сентября 1997 г. № 125-Ф3 «0 свободе совести и о религиозных объединенияХ» [25];

3.5. Порядок проведения публичных мероприятий регламентируется Федеральным законом № 54-ФЗ;

3.6. Оказание содействия организаторам массовых мероприятий в обеспечении безопасности граждан и общественного порядка в местах проведения данных мероприятий установлено п. 6 ч. 1 ст. 12 Федерального закона «О полиции»;

3.7. Регулирование правоотношений, возникающих при проведении массовых спортивных мероприятий, установлено Федеральным законом от 23 июля 2013 г. № 192-Ф3 «0 внесении изменений в отдельные законодательные акты Российской Федерации в связи с обеспечением общественного порядка и общественной безопасности при проведении официальных спортивных соревнований», которым внесены изменения в Федеральный закон от 4 декабря 2007 г. № 329Ф3 «0 физической культуре и спорте в Российской Федерации» [26], а также Постановление Правительства Российской Федерации от 16 декабря 2013 г. № 1156 «Об утверждении Правил поведения зрителей при проведении официальных спортивных соревнований» [27] и Постановлением Правительства Российской Федерации от 18 апреля 2014 г. № 353 «Об утверждении Правил обеспечения безопасности при проведении официальных спортивных соревнований» [28];

3.8. Порядок проведения Олимпийских зимних игр и XI Паралимпийских зимних игр 2014 г. в г. Сочи регламентируется Указом Президента Российской Федерации от 19 августа 2013 г. № 686 «Об особенностях применения усиленных мер безопасности в период проведения XXII Олимпийских зимних игр и XI Паралимпийских зимних игр 2014 года в г. Сочи» [29];

3.9. Обеспечение правопорядка при массовых мероприятиях, своевременное реагирование и пресечение попыток нарушений установленного порядка их проведения предусмотрено ст. 6 Приказа МВД России от 29 января 2008 г. № 80 
«Вопросы организации деятельности строевых подразделений патрульно-постовой службы полиции» (вместе с «Уставом патрульно-постовой службы полиции») [30].

Однако на основе анализа нормативных правовых актов в рассматриваемой сфере можно прийти к выводу, что правовой основой обеспечен только порядок организации и проведения публичных мероприятий, выборов в органы государственной власти и органы местного самоуправления, части религиозных мероприятий в то время как порядок организации и проведения иных массовых мероприятий, количество проведения которых больше по сравнению с публичными мероприятиями, регламентируется нормативными правовыми актами субъектов Российской Федерации.

Подобные полномочия субъектов Российской Федерации вытекают из положений Конституции Российской Федерации, согласно которым в совместном ведении Российской Федерации и субъектов Российской Федерации находится обеспечение законности, правопорядка, общественной безопасности.

Так, во многих субъектах Российской Федерации принимаются нормативные правовые акты, регламентирующие порядок организации и проведения иных массовых мероприятий (культурнопросветительских, зрелищных, рекламных, спортивных и т. д.), обеспечение охраны общественного порядка при проведении названных мероприятий.

Например, в Республике Саха (Якутия) и Магаданской области приняты нормативные правовые акты, призванные регулировать порядок организации и проведения иных видов массовых мероприятий.

Так, Постановлением Правительства Республики Саха (Якутия) от 16 мая 2011 г. № 203 утвержден порядок организации и обеспечения общественной безопасности в период подготовки и проведения общественно-политических, культурно-зрелищных и спортивно-массовых мероприятий на территории Республики Саха (Якутия) [31].

Кроме того, в Приморском крае, Амурской области, Сахалинской области законодательные акты, регламентирующие порядок организации и проведения массовых мероприятий (культурнопросветительских, театрально-зрелищных, спортивных, рекламных и т. д.) приняты в отдельных городских округах, муниципальных районах, но не на всей территории названных субъектов Российской Федерации.

К примеру, постановлением администрации Пограничного муниципального района Приморского края от 24 января 2013 г. № 38 «0 порядке проведения культурно-просветительских, театральнозрелищных, спортивных массовых мероприятий на территории Пограничного муниципального района» предусмотрен порядок организации и проведения культурно-просветительских, театральнозрелищных, спортивных массовых мероприятий на территории Пограничного муниципального района Приморского края [32].

Напротив, в Хабаровском крае, Камчатском крае, Чукотском автономном округе отсутствуют нормативные правовые акты, призванные регулировать порядок организации и проведения массовых мероприятий (культурно-просветительских, театрально-зрелищных, спортивных, рекламных и т. д.).

Таким образом, совокупность несогласованных правовых норм в данной сфере не позволяет выработать единую правовую модель административной ответственности за нарушение общественного порядка и общественной безопасности при проведении массовых мероприятий.

Однако если определить направления правового регулирования, выработать необходимые критерии и целесообразно их использовать, то можно получить единую, носящую организационный характер, систему нормативных правовых актов, правоприменительной практики, направленную на регулирование общественных отношений, складывающихся в ходе организации и проведения массовых мероприятий.

Отметим, что указанная система должна учитывать процессы, которые протекают в обществе в связи с проведением любого массового мероприятия, но не подстраиваться под них, поскольку является ориентиром и призвана регулировать эти процессы.

В этой связи нами предлагается разработка правовой модели административной ответственности в указанной сфере, которая должна содержать две стороны: внешнюю и внутреннюю $[33$, c. 22].

Первая - это иерархическая совокупность различных нормативных правовых актов и содержащихся в них правовых норм, относящихся к вопросам привлечения к административной ответственности за нарушение общественного порядка и обеспечения общественной безопасности при проведении массовых мероприятий (международного уровня, федерального уровня, уровня субъектов Российской Федерации и т.д.).

Вторая - содержательная сторона - представляет концепцию правового регулирования в рассматриваемой сфере. В этом документе следует раскрыть значение и содержание правовых норм, которые используются в сфере охраны общественного порядка и обеспечения общественной безопасности при проведении массовых мероприятий, что позволит определить направление развития 


\section{Административное и муниципальное право $10(94) \cdot 2015$}

законодательства и государственной политики в исследуемой сфере.

Все элементы первой и второй стороны обладают своими организационными характеристиками, ввиду того, что следует организовать законодательный материал, выстроить его иерархию, а также исключить противоречия.

В данном контексте возникает закономерный вопрос об увеличении количества нормативных правовых актов в данной сфере в связи с разработкой предлагаемой модели. Однако ранее отмечалось, что правовое регулирование административной ответственности за нарушение общественного порядка и общественной безопасности при про- ведении массовых мероприятий представлено большим объемом нормативных правовых актов, которые имеют разрозненный характер. Поэтому в данном случае построение общей правовой модели способствует устранению некоторых недостатков, а также конкретизации положений, которые оставлены без внимания.

Вместе с тем, что касается потенциальных участников массовых мероприятий, которые соберутся проводить данные акции, то создание правовой модели в исследуемой сфере будет иметь для них особое значение, поскольку принимая решение о проведении того или иного мероприятия, следует знать о состоянии правового регулирования.

\section{Библиография:}

1. Бабаева В. К. Общая теория права : курс лекций. Нижний Новгород, 1993.

2. Всеобщая декларация прав человека от 10 декабря 1948 г. // Рос. газета 1995. № 67. 5 апреля.

3. Об экономических, социальных и культурных правах : Международный пакт от 16 декабря 1966 г. // Бюллетень Верховного суда РФ. № 12.1994.

4. 0 гражданских и политических правах : Международный Пакт от 16 декабря 1966 г. // Бюллетень Верховного суда РФ. № 12.1994.

5. О собраниях, митингах, демонстрациях, шествиях и пикетированиях : федеральный закон от 19 июня 2004 г. № 54-Ф3 // Рос. газета. 2004. № 131. 23 июня.

6. О статусе военнослужащих : федеральный закон от 27 мая 1998 г. № 76-ФЗ // Собр. законодательства Рос. Федерации. 1998. № 22. Ст. 2331.

7. О политических партиях : федеральный закон от 11 июля 2001 г. № 95-Ф3 // Собр. законодательства Рос. Федерации. 2001. № 29. Ст. 2950.

8. Окуньков Л. А. Комментарий к Конституции Российской Федерации. М., 1994.

9. Иванец Г. И., Калинский И. В., Червонюк В. И. Комментарий к Конституции Российской Федерации. М., 2001.

10. Зорькин В. Д., Лазарева Л. В. Комментарий к Конституции Российской Федерации. М., 2009.

11. Вашкевич А. Е. Спонтанные собрания: национальное законодательство европейских стран и прецедентное право Европейского суда по правам человека // Сравнительное конституционное обозрение. 2013. № 2.

12. Нудненко Л. А. Проблемы правового регулирования конституционного права гражданина России на публичные мероприятия // Конституционное и муниципальное право. 2006. № 6.

13. Полянская И.С. Конституционно-правовое регулирование права граждан Российской Федерации на проведение собраний, митингов и демонстраций, шествий и пикетирования : автореф. дис. ... канд. юрид. наук : 12.00 .02 / Полянская Ирина Станиславовна. М., 2005.

14. БДИПЧ ОБСЕ. Руководящие принципы по свободе мирных собраний. Венецианская комиссия Совета Европы [Электронный ресурс]. Режим доступа: http://www.osce.org/. (дата обращения: 18.04.2015 г.).

15. Доклад Уполномоченного по правам человека в РФ от 19 февраля 2013 г. «Доклад Уполномоченного по правам человека в Российской Федерации за 2012 год // Рос. газета. 2013. № 68. 29 марта.

16. Авакьян С. А. Свобода общественного мнения и конституционно-правовые гарантии ее осуществления // Конституционное и муниципальное право. 2013. № 1.

17. О чрезвычайном положении : федеральный конституционный закон от 30 мая 2001 г. № 3-ФК3 // Собр. законодательства Рос. Федерации. 2001. № 23. Ст. 2277.

18. О военном положении : федеральный конституционный закон от 30 января 2002 г. № 1-ФКЗ // Собр. законодательства Рос. Федерации. 2002. №5. Ст. 375.

19. Об общественных объединениях : федеральный закон от 19 мая 1995 г. № 82-ФЗ // Собр. законодательства Рос. Федерации. 1995. № 21. Ст. 1930.

20. О противодействии экстремистской деятельности : федеральный закон от 25 июля 2002 г. № 114-Ф3 // Собр. законодательства Рос. Федерации. 2002. № 30. Ст. 3031.

21. Вопросы организации деятельности участковых уполномоченных полиции : приказ МВд России от 31 декабря 2012 г. № 1166 // Рос. газета. 2013. № 65. 27 марта.

22. О референдуме Российской Федерации : федеральный конституционный закон от 28 июня 2004 г. № 5-ФКЗ // Собр. законодательства Рос. Федерации. 2004. № 27. Ст. 2710.

23. О Государственной границе Российской Федерации : закон Российской Федерации от 1 апреля 1993 г. № $4730-1$ // Рос. газета. 1993. № 84. 4 мая.

24. О внутренних войсках Министерства внутренних дел Российской Федерации : федеральный закон от 6 февраля 1997 г. № 27-Ф3 // Собр. законодательства Рос. Федерации. 1997. № 6. Ст. 711.

25. О свободе совести и о религиозных объединениях : федеральный закон от 26 сентября 1997 г. № 125 -Ф3 // Собр. законодательства Рос. Федерации. 1997. № 39. Ст. 4465. 
26. О внесении изменений в отдельные законодательные акты Российской Федерации в связи с обеспечением общественного порядка и общественной безопасности при проведении официальных спортивных соревнований : федеральный закон от 23 июля 2013 г. № 192-ФЗ [Электронный ресурс]. Режим доступа: Официальный интернет-портал правовой информации. URL: http://www.pravo.gov.ru. (дата обращения: 18.04.2015 г.).

27. Об утверждении Правил поведения зрителей при проведении официальных спортивных соревнований : постановление Правительства Российской Федерации от 16 декабря 2013 г. № 1156 // Рос. газета. 2013. № 286. 19 декабря.

28. об утверждении Правил обеспечения безопасности при проведении официальных спортивных соревнований : постановлением Правительства Российской Федерации от 18 апреля 2014 г. № 353 // Рос. газета. 2014. № 92. 23 апреля.

29. Об особенностях применения усиленных мер безопасности в период проведения XXII Олимпийских зимних игр и XI Паралимпиайских зимних игр 2014 года в г. Сочи : указ Президента Российской Федерации от 19 августа 2013 г. № 686 // Рос. газета. 2013. № 187. 23 августа.

30. Вопросы организации деятельности строевых подразделений патрульно-постовой службы полиции» (вместе с «Уставом патрульно-постовой службы полиции») : приказ МВД России от 29 января 2008 г. № 80 // Бюллетень нормативных актов федеральных органов исполнительной власти. 2008. № 27.7 июля.

31. Об организации обеспечения правопорядка и общественной безопасности в период подготовки и проведения общественно-политических, культурно-зрелищных и спортивно-массовых мероприятий на территории Республики Саха (Якутия) : постановление Правительства РС(Я) от 16 мая 2011 г. № 203 // Якутия. 2011. № 91. 25 мая.

32. О порядке проведения культурно-просветительских, театрально-зрелищных, спортивных массовых мероприятий на территории Пограничного муниципального района : постановление администрации Пограничного муниципального района Приморского края от 24 января 2013 г. № 38 // Вестник Приграничья. 2013. №15(10545). 9 февраля.

33. Хабриева Т. Я. Правовая политика государства в сфере миграции населения // Миграционное право. 2006. № 1.

\section{References (transliterated):}

1. Babaeva V. K. Obshchaya teoriya prava : kurs lektsii. Nizhnii Novgorod, 1993.

2. Vseobshchaya deklaratsiya prav cheloveka ot 10 dekabrya 1948 g. // Ros. gazeta 1995. № 67. 5 aprelya.

3. Ob ekonomicheskikh, sotsial'nykh i kul'turnykh pravakh : Mezhdunarodnyi pakt ot 16 dekabrya 1966 g. // Byulleten' Verkhovnogo suda RF. № 12. 1994.

4. O grazhdanskikh i politicheskikh pravakh : Mezhdunarodnyi Pakt ot 16 dekabrya 1966 g. // Byulleten' Verkhovnogo suda RF. № 12. 1994.

5. O sobraniyakh, mitingakh, demonstratsiyakh, shestviyakh i piketirovaniyakh : federal'nyi zakon ot 19 iyunya 2004 g. № 54-FZ // Ros. gazeta. 2004. № 131. 23 iyunya.

6. O statuse voennosluzhashchikh : federal'nyi zakon ot 27 maya 1998 g. № 76-FZ // Sobr. zakonodatel'stva Ros. Federatsii. 1998. № 22. St. 2331.

7. 0 politicheskikh partiyakh : federal'nyi zakon ot 11 iyulya 2001 g. № 95-FZ // Sobr. zakonodatel'stva Ros. Federatsii. 2001. № 29. St. 2950.

8. Okun'kov L. A. Kommentarii k Konstitutsii Rossiiskoi Federatsii. M., 1994.

9. Ivanets G. I., Kalinskii I. V., Chervonyuk V. I. Kommentarii k Konstitutsii Rossiiskoi Federatsii. M., 2001.

10. Zor'kin V. D., Lazareva L. V. Kommentarii k Konstitutsii Rossiiskoi Federatsii. M., 2009.

11. Vashkevich A. E. Spontannye sobraniya: natsional'noe zakonodatel'stvo evropeiskikh stran i pretsedentnoe pravo Evropeiskogo suda po pravam cheloveka // Sravnitel'noe konstitutsionnoe obozrenie. 2013. № 2.

12. Nudnenko L. A. Problemy pravovogo regulirovaniya konstitutsionnogo prava grazhdanina Rossii na publichnye meropriyatiya // Konstitutsionnoe i munitsipal'noe pravo. 2006. № 6.

13. Polyanskaya I.S. Konstitutsionno-pravovoe regulirovanie prava grazhdan Rossiiskoi Federatsii na provedenie sobranii, mitingov i demonstratsii, shestvii i piketirovaniya : avtoref. dis. ... kand. yurid. nauk : 12.00 .02 / Polyanskaya Irina Stanislavovna. M., 2005.

14. BDIPCh OBSE. Rukovodyashchie printsipy po svobode mirnykh sobranii. Venetsianskaya komissiya Soveta Evropy [Elektronnyi resurs]. Rezhim dostupa: http://www.osce.org/. (data obrashcheniya: 18.04.2015 g.).

15. Doklad Upolnomochennogo po pravam cheloveka v RF ot 19 fevralya 2013 g. «Doklad Upolnomochennogo po pravam cheloveka v Rossiiskoi Federatsii za 2012 god // Ros. gazeta. 2013. № 68. 29 marta.

16. Avak'yan S. A. Svoboda obshchestvennogo mneniya i konstitutsionno-pravovye garantii ee osushchestvleniya // Konstitutsionnoe i munitsipal'noe pravo. 2013. № 1.

17. O chrezvychainom polozhenii : federal'nyi konstitutsionnyi zakon ot 30 maya 2001 g. № 3-FKZ // Sobr. zakonodatel'stva Ros. Federatsii. 2001. № 23. St. 2277.

18. O voennom polozhenii : federal'nyi konstitutsionnyi zakon ot 30 yanvarya 2002 g. № 1-FKZ // Sobr. zakonodatel'stva Ros. Federatsii. 2002. №5. St. 375.

19. Ob obshchestvennykh ob"edineniyakh : federal'nyi zakon ot 19 maya 1995 g. № 82-FZ // Sobr. zakonodatel'stva Ros. Federatsii. 1995. № 21. St. 1930.

20. O protivodeistvii ekstremistskoi deyatel'nosti : federal'nyi zakon ot 25 iyulya 2002 g. № 114-FZ // Sobr. zakonodatel'stva Ros. Federatsii. 2002. № 30. St. 3031.

21. Voprosy organizatsii deyatel'nosti uchastkovykh upolnomochennykh politsii : prikaz MVD Rossii ot 31 dekabrya 2012 g. № 1166 // Ros. gazeta. 2013. № 65. 27 marta. 


\section{Административное и муниципальное право 10 (94) • 2015}

22. O referendume Rossiiskoi Federatsii : federal'nyi konstitutsionnyi zakon ot 28 iyunya 2004 g. № 5-FKZ // Sobr. zakonodatel'stva Ros. Federatsii. 2004. № 27. St. 2710.

23. O Gosudarstvennoi granitse Rossiiskoi Federatsii : zakon Rossiiskoi Federatsii ot 1 aprelya 1993 g. № $4730-1$ // Ros. gazeta. 1993. № 84.4 maya.

24. O vnutrennikh voiskakh Ministerstva vnutrennikh del Rossiiskoi Federatsii : federal'nyi zakon ot 6 fevralya 1997 g. № 27-FZ // Sobr. zakonodatel'stva Ros. Federatsii. 1997. № 6. St. 711.

25. O svobode sovesti i o religioznykh ob"edineniyakh : federal'nyi zakon ot 26 sentyabrya 1997 g. № 125-FZ // Sobr. zakonodatel'stva Ros. Federatsii. 1997. № 39. St. 4465.

26. 0 vnesenii izmenenii v otdel'nye zakonodatel'nye akty Rossiiskoi Federatsii v svyazi s obespecheniem obshchestvennogo poryadka i obshchestvennoi bezopasnosti pri provedenii ofitsial'nykh sportivnykh sorevnovanii : federal'nyi zakon ot 23 iyulya 2013 g. № 192-FZ [Elektronnyi resurs]. Rezhim dostupa: Ofitsial'nyi internet-portal pravovoi informatsii. URL: http://www.pravo.gov.ru. (data obrashcheniya: 18.04.2015 g.).

27. Ob utverzhdenii Pravil povedeniya zritelei pri provedenii ofitsial'nykh sportivnykh sorevnovanii : postanovlenie Pravitel'stva Rossiiskoi Federatsii ot 16 dekabrya 2013 g. № 1156 // Ros. gazeta. 2013. № 286. 19 dekabrya.

28. Ob utverzhdenii Pravil obespecheniya bezopasnosti pri provedenii ofitsial'nykh sportivnykh sorevnovanii: postanovleniem Pravitel'stva Rossiiskoi Federatsii ot 18 aprelya 2014 g. № 353 // Ros. gazeta. 2014. № 92. 23 aprelya.

29. Ob osobennostyakh primeneniya usilennykh mer bezopasnosti v period provedeniya XXII Olimpiiskikh zimnikh igr i XI Paralimpiaiskikh zimnikh igr 2014 goda v g. Sochi : ukaz Prezidenta Rossiiskoi Federatsii ot 19 avgusta 2013 g. № 686 // Ros. gazeta. 2013. № 187. 23 avgusta.

30. Voprosy organizatsii deyatel'nosti stroevykh podrazdelenii patrul'no-postovoi sluzhby politsii» (vmeste $s$ «Ustavom patrul'no-postovoi sluzhby politsii») : prikaz MVD Rossii ot 29 yanvarya 2008 g. № 80 // Byulleten' normativnykh aktov federal'nykh organov ispolnitel'noi vlasti. 2008. № 27. 7 iyulya.

31. Ob organizatsii obespecheniya pravoporyadka i obshchestvennoi bezopasnosti v period podgotovki i provedeniya obshchestvenno-politicheskikh, kul'turno-zrelishchnykh i sportivno-massovykh meropriyatii na territorii Respubliki Sakha (Yakutiya) : postanovlenie Pravitel'stva RS(Ya) ot 16 maya 2011 g. № 203 // Yakutiya. 2011. № 91.25 maya.

32. O poryadke provedeniya kul'turno-prosvetitel'skikh, teatral'no-zrelishchnykh, sportivnykh massovykh meropriyatii na territorii Pogranichnogo munitsipal'nogo raiona : postanovlenie administratsii Pogranichnogo munitsipal'nogo raiona Primorskogo kraya ot 24 yanvarya 2013 g. № 38 // Vestnik Prigranich'ya. 2013. №15(10545). 9 fevralya.

33. Khabrieva T. Ya. Pravovaya politika gosudarstva v sfere migratsii naseleniya // Migratsionnoe pravo. 2006 . № 1. 